Kansas State University Libraries

New Prairie Press

\title{
USING RESPONSE SURFACE METHODOLOGY WITH A MULTIVARIATE RESPONSE TO IMPROVE THE QUAIITY OF A FOOD PRODUCT
}

George A. Milliken

Tanya W. MacLaurin

Carole S. Setser

Follow this and additional works at: https://newprairiepress.org/agstatconference

Part of the Agriculture Commons, and the Applied Statistics Commons

\section{(c) (1) $(9$}

This work is licensed under a Creative Commons Attribution-Noncommercial-No Derivative Works 4.0 License.

\section{Recommended Citation}

Milliken, George A.; MacLaurin, Tanya W.; and Setser, Carole S. (1990). "USING RESPONSE SURFACE METHODOLOGY WITH A MULTIVARIATE RESPONSE TO IMPROVE THE QUAIITY OF A FOOD PRODUCT," Conference on Applied Statistics in Agriculture. https://doi.org/10.4148/2475-7772.1431

This is brought to you for free and open access by the Conferences at New Prairie Press. It has been accepted for inclusion in Conference on Applied Statistics in Agriculture by an authorized administrator of New Prairie Press. For more information, please contact cads@k-state.edu. 


\title{
USING RESPONSE SURFACE METHODOLOGY WTTH A MULTIVARIATE RESPONSE TO IMPROVE THE QUALITY OF A FOOD PRODUCT
}

\author{
George A. Milliken, Department of Statistics \\ Tanya W. MacLaurin, Department of Hotel, Restaurant and \\ Institutional Management and Dietetics \\ Carole S. Setser, Department of Foods and Nutrition \\ Kansas State University
}

\section{Introduction}

Nutrition in health is a major area of focus in our national health priorities as we move into the $21^{\text {st }}$ century. The government, food industry, food scientists, health professionals, and all disciplines that can assist need to work together in the development of "healthful food products" and encourage Americans to make healthful food choices (Drishell, 1990). Experimentation science provides strategies for helping food scientists improve existing food products and develop new ones. This paper describes a process where design of experiments and response surface methodology were utilized in the formulation development to guide product development of a healthful muffin that would meet predetermined nutritional parameters and reasonable sensory quality characteristics.

A Box-Behnken design (Mason et. al. 1989) for four factors with a center point, providing a total of 25 runs was conducted. A batch of muffins was made from each formulation. A single muffin from each batch was selected as the experimental unit. Each muffin was scored for nine sensory characteristics by two trained-experienced food scientists in the laboratory. Based on previous research concerning composition of sensory evaluation panels, the mean of the two determinations for each characteristic was used as the response (Basker (1977), Chambers et. al. (1981)). Each measured characteristic had a target value, called the optimum value, which was determined prior to conducting the experiment. The data used in the analyses consisted of the absolute value of the measurement minus the optimum value. Thus the optimum formulation would be that set of factors producing the minimum response. A quadratic response surface model was fit to the data for each of the nine characteristics. The fitted response surfaces generally had maximums or saddle points and not minimums. Thus the results from the univariate response surface analyses did not provide a resolution of the optimum muffin formulation. The next step was to construct a score for each muffin by taking a weighted linear combination of the nine responses. The fitted response surface had a maximum indicating the optimum muffin formulation occurred on the boundary of the factor space. Two formulations were selected and modified further to provide an optimal formulation. The following sections discuss the need for healthful food product development, research objectives for the development of a healthful muffin formulation, the experimental design, details of the analyses, construction of the score function and selection and testing of the final muffin formulation. 


\section{The Nutritional Background}

Good health is the product of complex interactions among environmental, behavioral, social and genetic factors. Some of these factors can be controlled while others can not. Personal behavior is controllable and influences chances for good health. Exercise, smoking, consumption of alcoholic beverages and engaging in high risk activities that increase the risk of disease or disability influence our health as well as what we eat. National health statistics display the vital role that diet plays in good health. Of 2.1 million total deaths in 1987, 1.5 were either attributable to diet or diet contributed a significant effect (National Center for Health Statistics, 1988).

Dietary Guidelines for Americans issued jointly by the Department of Agriculture and the Department of Health and Human Services in 1985 recommended that Americans need to:

* Eat a variety of foods.

* Maintain desirable weight.

* Avoid too much fat, saturated fat, and cholesterol.

* Eat foods with adequate starch and fiber.

* Avoid too much sugar.

* Avoid too much sodium.

* Drink alcoholic beverages in moderation.

The Surgeon General's (1988) report expanded the focus of these seven guidelines and prioritizes the areas for dietary change.

* Reduce fat consumption (saturated fat and cholesterol). The American Heart and the American Cancer Society and National Cholesterol Eduction Program recommend $30 \%$ of total calories obtained from fat with less than $10 \%$ of these from saturated fats. Cholesterol consumption should not exceed 300 milligrams a day.

* Achieve and maintain a desirable body weight.

* Increase consumption of whole grain foods, cereal products, vegetables, fruits and fiber.

* Reduce and monitor consumption of sodium.

* Consume alcohol in moderation.

* Water fluoridation should be practiced.

* Limit consumption of sugar.

* Increase consumption of calcium and iron for women and adolescents.

These dietary recommendations and priorities indicate that diet must be a major focal point in lifestyle for the attainment of good health. The food industry can assist in the attainment of good health by creating and modifying products that have an enhanced nutrition profile (Hopper, 1990). The present research was designed to acquire data and insight into the development, acceptability and marketability of a healthful muffin. The research objectives were: 
1. To develop a formulation for a healthful muffin that meets the dietary priorities established in the Surgeon General's Report, The Dietary Guidelines for Americans (1985) and the dietary recommendations of the American Heart Association. The muffin must be low in saturated fat, cholesterol and salt. Less than $30 \%$ of the calories should be contributed from fat, not more than $10 \%$ of these from saturated fat. The muffins should be high in fiber and utilize a fat high in polyunsaturated fatty acids.

2. The healthful muffin must meet reasonable sensory quality expectations for a high quality muffin. It must have a slightly rounded to moderately pebbly cracked top with uniform even interior cell structure devoid of tunnels and have a pleasant blended flavor.

A formulation (Table 1) currently being utilized in Kansas State Residence Hall Dining Services was used as the control from which the healthful alternative formulation was developed.

\begin{tabular}{lr}
\hline \multicolumn{2}{c}{ Table 1. Base muffin } \\
formula. \\
HONEY WHEAT MUFFINS \\
WT(g) \\
\multicolumn{2}{c}{ WT } \\
& 23.40 \\
Whole eggs & 66.78 \\
Water & 50.07 \\
Oil & 45.51 \\
Honey & 48.57 \\
Flour, all purpose & 59.19 \\
Flour, whole wheat & 5.76 \\
Baking powder & 2.88 \\
Salt & \\
\hline
\end{tabular}

To make the muffin formulation more healthful the following alterations and substitutions were made:

* A frozen cholesterol free whole egg substitute was used for whole eggs.

* Canola oil high in polyunsaturated fatty acids, was used.

* Oat bran was substituted for whole wheat flour and added to the highest possible level before objectionable sensory characteristics developed.

* Sodium was decreased.

* Polydextrose, carboxylmethylcellulose and egg white powder were utilized to assist in meeting reasonable structural and textural qualities.

Bench top evaluation of nine sensory characteristics was performed using a sensory ballot developed for healthful muffins. The muffin attributes were evaluated on a five point scale for pebbling, cracking, roundedness, tunneling, firmness, crumbliness, initial mouth dryness, cohesiveness of mass and dryness after chewing. To obtain a "healthful" high fiber, low fat muffin with similar sensory characteristics to the low fiber, high fat control muffin, alterations 
were made to the formulation. These began by modifying one ingredient at a time, fiber first then oil. By doing one ingredient at a time usable extremes of each were determined. The alterations and substitutions in the formulation caused changes to occur in the sensory attributes of the muffin. Knowing how each ingredient functioned independently, interacted with other ingredients in the formulation and how this affected the sensory characteristics of the product produced a vast number of possible ingredient level manipulations. After much experimentation with the formulation, the fiber level was at the highest level possible, sodium was decreased, no cholesterol was present, however the fat content was too high and the muffin was dry and crumbly. Four ingredients (oil, water, polydextrose and egg white protein) were targeted to be manipulated using a RSM to optimize for reasonable structural, textural and moistness characteristics similar to the high fat control. (Giovanni, 1983 and Joglekar and May, 1987).

The Design:

Four important factors were known to influence the quality of the muffins related to fat level, crumbliness and moistness. The four factors are amount of OIL, amount of WATER, amount of POLYDEXTROSE and the amount of EGG White Protein. The levels of the factors are in Table 2.

Table 2. The levels of the four factors used in the experiments.

\begin{tabular}{cccc} 
FACTOR & Levels (grams) \\
\hline OIL & 25 & 30 & 35 \\
WATER & 110 & 120 & 130 \\
POLY & 4 & 8 & 12 \\
EGG WP & 4 & 11 & 18 \\
\hline
\end{tabular}

A Box-Behnken design (see Table 3) with one center point providing a total of 25 runs was selected and one batch of muffins was produced for each ingredient combination. A muffin was randomly selected from each batch as the experimental unit and was rated by two trained-experienced food scientists. Two types of characteristics were measured, appearance characteristics and sensory characteristics, as listed in Table 4. Also included in Table 4 are the optimal values for each measured characteristic. Optimum values were arbitrarily assessed by the food scientists based upon their experience, training and best judgement. A listing of the data is in Table 10. In order to construct a variable which can be used in response surface methodology, each measured characteristic was transformed to the absolute value of the deviation of the measured value from the optimum value. Thus the optimum muffin formulation occurs for the minimum value of the transformed characteristics.

\section{Analysis for each Characteristic}

A general quadratic response surface model was fit to the data for each transformed characteristic using PROC RSREG of the SAS system (1987). PROC RSREG fits the quadratic model and determines the resulting critical value. Table 5 presents a summary of the critical values for each variable. For each characteristic, the levels of the four factors at 
which the critical value occurs, the magnitude of the model at that point and the type of critical value are included in Table 5.

Table 3. The Box-Behnken Design where -1 denotes low level, 0 middle level and 1 high level of the respective ingredient.

O - OIL, $\mathrm{H}=$ WATER, $\mathrm{P}=$ POLY-dextrose, $\mathrm{E}=$ Egg White Powder

\begin{tabular}{cccccccccc} 
RUN & O & H & P & E & RUN & O & H & P & E \\
1 & 1 & 1 & 0 & 0 & 14 & 0 & 1 & 1 & 0 \\
2 & 1 & -1 & 0 & 0 & 15 & 0 & 1 & -1 & 0 \\
3 & -1 & 1 & 0 & 0 & 16 & 0 & -1 & 1 & 0 \\
4 & -1 & -1 & 0 & 0 & 17 & 0 & -1 & -1 & 0 \\
5 & 0 & 0 & 1 & 1 & 18 & 1 & 0 & 1 & 0 \\
6 & 0 & 0 & 1 & -1 & 19 & 1 & 0 & -1 & 0 \\
7 & 0 & 0 & -1 & 1 & 20 & -1 & 0 & 1 & 0 \\
8 & 0 & 0 & -1 & -1 & 21 & -1 & 0 & -1 & 0 \\
9 & 0 & 0 & 0 & 0 & 22 & 0 & 1 & 0 & 1 \\
10 & 1 & 0 & 0 & 1 & 23 & 0 & 1 & 0 & -1 \\
11 & 1 & 0 & 0 & -1 & 24 & 0 & -1 & 0 & 1 \\
12 & -1 & 0 & 0 & 1 & 25 & 0 & -1 & 0 & -1 \\
13 & -1 & 0 & 0 & -1 & & & & & \\
\hline
\end{tabular}

Table 4. Characteristics measured on each muffin and the respective optimum values.

\begin{tabular}{lcc} 
Appearance Characteristics & & Optimum value \\
\cline { 1 - 1 } Pebbling & & 3.0 \\
Cracking & 3.0 \\
Rounded & 4.0 \\
Tunneling & 1.0 \\
Sensory Characteristics & & Optimum value \\
\cline { 1 - 1 } Firmness & & 2.5 \\
Initial mouth dryness & 1.5 \\
Crumbliness & 2.0 \\
Cohesiveness of mass & 2.5 \\
Dryness after chewing & 1.5
\end{tabular}

five point scale: 1 = none, 2 = slight, 3 = moderate, $4=$ much, $5=$ extreme 
Table 5. Summary of Response Surface Models.

\begin{tabular}{lccrcccc} 
Variable & $\mathrm{O}$ & $\mathrm{H}$ & $\mathrm{E}$ & $\mathrm{P}$ & Pred. Response & Type \\
Pebbling & 30.5 & 122.0 & 14.1 & 7.7 & .4 & Saddle point \\
Cracking & 38.3 & 150.0 & 27.3 & 6.7 & .0 & Saddle point \\
rounded & 26.2 & 126.6 & 1.0 & 3.4 & .4 & Saddle point \\
Tunneling & 30.8 & 125.5 & 13.4 & 8.2 & 3.1 & Maximum \\
Firmness & 31.2 & 121.5 & 6.7 & 8.5 & -.3 & Minimum \\
I.M. Dryness & 11.3 & 151.6 & -16.6 & -4.6 & -1.6 & Saddle point \\
Crumbliness & 29.6 & 114.0 & 14.8 & 9.1 & 1.0 & Saddle point \\
C. of Mass & 27.2 & 131.7 & 6.6 & .7 & 0.2 & Saddle point \\
Dry a. chew & 31.6 & 115.1 & 4.8 & 9.9 & -.3 & Minimum \\
\hline
\end{tabular}

Table 6. Grouping of Variables with Importance Groups.

\begin{tabular}{cl} 
Grouping & \multicolumn{1}{c}{ Variables } \\
\hline 1 & Tunneling \\
2 & Cohesiveness of mass, Dryness after chewing \\
3 & Firmness, Crumbliness, Initial mouth dryness \\
4 & Pebbling, cracking, rounded \\
\hline
\end{tabular}

One maximum and six saddle points were found, thus the individual variable analyses did not resolve the problem and provide an optimum muffin formulation.

\section{The Score}

Since the analyses of the individual variables provide unsettling and conflicting results as to the optimum muffin formulation, a score was computed for each muffin as a weighted linear combination of the measured characteristics. The approach is similar to the selection index used in working with multivariate characteristics in genetic selection experiments (Falconer (1964)). To construct the weights, the variables were grouped as to degree of importance, forming four groups (see Table 6). The score was computed by weighing the characteristics in importance group $\mathrm{k}$ by $1 / \mathrm{k}$. Thus the score was computed as SCORE $=$ Tunneling $+1 / 2$ (Coh. of Mass + Dry after chew $)+1 / 3$ (Firmness + Crumbliness + In. Mouth Dry) $+1 / 4$ (Pebbling + Cracking + Roundedness). Since all values are absolute deviations from their optimums, the optimum value of the Score variable is zero.

The quadratic response surface model was fit to the SCORE data via PROC RSREG where the critical value was a saddle point at $0=31.1, \mathrm{H}=114.9, \mathrm{E}=13.9$ and $\mathrm{P}=9.0$ and a predicted value of 4.4. Several of the coefficients in the quadratic response surface model were not significantly different from zero. Thus stepwise regression strategies were used to determine a more concise model. The resulting model involved $0, \mathrm{H}, \mathrm{E}, \mathrm{O}^{2}, \mathrm{P}^{2}, \mathrm{E}^{2}, \mathrm{OP}$ and $E \mathrm{H}$, where the coefficients of $\mathrm{O}^{2}, \mathrm{P}^{2}$ and $\mathrm{E}^{2}$ were all negative (see Table 7). Thus the surface did not have a minimum. Table 7 contains the estimates of the parameters of the model as well as the standard errors and the analysis of variance results. The next step was to investigate the response surface by generating a grid over the design space (see Table 8), 
compute predicted values via the model at each design point and search for areas in the design space whose predicted values were close to zero.

Next, all design points with predicted scores between -.4 and +.4 were selected (looking for points in the design space where predicted score values were close to zero). Figures 1 though 6 are bivariate plots of those selected design points. The plots show the better formulations, those with predicted scores between -0.4 and +0.4 , occur on the boundary of the design space. Two formulations from the boundary were selected for further study and are listed in Table 9. The two formulations were evaluated and both had similar appearance and sensory attributes. Thus, the formulation utilizing 25 grams of oil was selected because of its lower fat content. The muffin met reasonable sensory quality expectations except for moistness. It was agreed that it was too moist, therefore was further modified by decreasing the polydextrose to 8 grams. The adopted formula (Table 9) was used as a basis for further development of healthful muffins utilizing various fiber sources.

Table 7. Results of the final model to describe SCORE.

Dependent Variable: SCORE

Analysis of Variance

$\begin{array}{lcccc}\begin{array}{l}\text { Source } \\ \text { Prob }>\text { F }\end{array} & \text { DF } & \begin{array}{c}\text { Sum of } \\ \text { Squares }\end{array} & \begin{array}{c}\text { Mean } \\ \text { Square }\end{array} & \text { F Value } \\ \begin{array}{l}\text { Model } \\ 0.0099\end{array} & 8 & 21.82918 & 2.72865 & 3.902 \\ \text { Error } & 16 & 11.18916 & 0.69932 & \\ \text { C Total } & 24 & 33.01833 & & \\ \quad & 0.83625 & \text { R-square } & 0.6611 \\ \text { Root MSE } & 3.11500 & \text { Adj R-sq } & 0.4917 \\ \text { Dep Mean } & 26.84606 & & \end{array}$

Parameter Estimates

\begin{tabular}{lcrccc}
\multicolumn{1}{c}{ Variable } & DF & $\begin{array}{c}\text { Parameter } \\
\text { Estimate }\end{array}$ & $\begin{array}{c}\text { Standard } \\
\text { Error }\end{array}$ & $\begin{array}{c}\text { T for HO: } \\
\text { Parameter }=0\end{array}$ & Prob $>|\mathrm{T}|$ \\
INTERCEP & 1 & -16.250828 & 15.58512220 & -1.043 & 0.3126 \\
O & 1 & 2.321424 & 0.86750766 & 2.676 & 0.0166 \\
H & 1 & -0.155456 & 0.07000009 & -2.221 & 0.0411 \\
E & 1 & -0.904326 & 0.73675537 & -1.227 & 0.2374 \\
OO & 1 & -0.041169 & 0.01486280 & -2.770 & 0.0137 \\
PP & 1 & -0.044392 & 0.02031586 & -2.185 & 0.0441 \\
EE & 1 & -0.016434 & 0.00758306 & -2.167 & 0.0457 \\
OP & 1 & -.025446 & 0.01092088 & 2.330 & 0.0332 \\
HE & 1 & 0.011607 & 0.00597325 & 1.943 & 0.0698
\end{tabular}

Table 8. Grid over Design Space.

$\mathrm{OIL}=25$ to 35 by 1

$\mathrm{H}_{2} \mathrm{O}=125$ to 130 by 1

Egg W P $=4$ to 7 by 1

Poly $D=4$ to 12 by 1 
Table 9. The two selected formulations and the adapted formulation.

\begin{tabular}{|c|c|c|c|c|}
\hline & OIL & WATER & $\begin{array}{c}\text { POLY- } \\
\text { DEXTROSE }\end{array}$ & $\begin{array}{c}\text { EGG WHITE } \\
\text { POWDER }\end{array}$ \\
\hline $\begin{array}{l}\text { Formulations } \\
\text { Selected }\end{array}$ & $25 \mathrm{~g}$ & $130 \mathrm{~g}$ & $12 \mathrm{~g}$ & $4 \mathrm{~g}$ \\
\hline $\begin{array}{l}\text { VIA Response } \\
\text { Surface Model }\end{array}$ & $35 \mathrm{~g}$ & $130 \mathrm{~g}$ & $4 \mathrm{~g}$ & $4 \mathrm{~g}$ \\
\hline Adapted Formula & $25 \mathrm{~g}$ & $130 \mathrm{~g}$ & $8 \mathrm{~g}$ & $4 \mathrm{~g}$ \\
\hline
\end{tabular}

Table 10. Data list where $\mathrm{OIL}=$ gms $\mathrm{OIL}, \mathrm{H} 2 \mathrm{O}=$ gms water, $\mathrm{POL}=$ gms Poiy-dextrose, $E W P=$ gms egg white powder, TUN=tunneling, CMASS = cohesiveness of mass, $\mathrm{DAC}=$ dryness after chewing, FIR = firmness, $C R U=$ crumbliness, $\mathrm{IMD}=$ initial mouth dryness, $\mathrm{PEB}=$ pebbling, $\mathrm{CRA}=$ cracking and $\mathrm{RND}=$ rounded.

OBS OIL H20 POL EWP TUN CMASS DAC FIR CRU IMD PEB CRA RND SCORE

$\begin{array}{rrrrrrrrrrrrrrr}1 & 30 & 120 & 12 & 18 & 1.5 & 1.5 & 2.5 & 5.0 & 1.5 & 3.0 & 2.5 & 4.0 & 4.0 & 9.2917 \\ 2 & 30 & 110 & 4 & 11 & 1.5 & 1.5 & 2.5 & 5.0 & 1.5 & 3.0 & 4.5 & 4.5 & 4.5 & 10.0417 \\ 3 & 30 & 130 & 4 & 11 & 1.5 & 2.5 & 2.0 & 3.0 & 2.0 & 1.5 & 4.0 & 4.5 & 4.0 & 9.0417 \\ 4 & 35 & 120 & 8 & 4 & 1.0 & 2.5 & 1.5 & 2.5 & 2.0 & 1.5 & 4.5 & 4.5 & 4.0 & 8.2500 \\ 5 & 25 & 110 & 8 & 11 & 2.0 & 2.0 & 2.5 & 4.5 & 1.5 & 2.0 & 4.5 & 3.5 & 4.5 & 10.0417 \\ 6 & 25 & 120 & 4 & 11 & 1.5 & 2.0 & 2.5 & 3.5 & 2.0 & 2.0 & 4.0 & 4.5 & 4.0 & 9.3750 \\ 7 & 25 & 120 & 8 & 18 & 2.0 & 2.5 & 2.5 & 5.0 & 1.5 & 2.5 & 3.0 & 3.0 & 4.5 & 10.1250 \\ 8 & 30 & 120 & 4 & 18 & 2.0 & 2.0 & 3.0 & 4.0 & 2.0 & 3.0 & 3.0 & 3.5 & 4.0 & 10.1250 \\ 9 & 35 & 110 & 8 & 11 & 2.5 & 4.0 & 2.0 & 2.0 & 2.5 & 2.5 & 2.5 & 2.5 & 3.5 & 9.9583 \\ 10 & 30 & 120 & 12 & 4 & 2.0 & 3.0 & 1.5 & 2.0 & 2.0 & 2.5 & 4.0 & 3.5 & 3.5 & 9.1667 \\ 11 & 30 & 110 & 8 & 4 & 2.5 & 2.5 & 1.5 & 2.0 & 4.0 & 2.0 & 4.0 & 4.0 & 3.5 & 10.0417 \\ 12 & 30 & 130 & 8 & 18 & 4.5 & 3.0 & 2.5 & 1.5 & 1.0 & 3.5 & 1.5 & 2.5 & 3.5 & 11.1250 \\ 13 & 30 & 120 & 8 & 11 & 4.0 & 2.0 & 1.5 & 2.5 & 3.0 & 2.0 & 3.5 & 3.5 & 3.5 & 10.8750 \\ 14 & 30 & 130 & 8 & 4 & 1.5 & 2.0 & 1.5 & 2.5 & 4.0 & 1.5 & 3.0 & 2.5 & 3.5 & 8.1667 \\ 15 & 30 & 110 & 12 & 11 & 3.5 & 3.5 & 1.5 & 1.5 & 2.5 & 2.5 & 2.0 & 3.5 & 3.0 & 10.2917 \\ 16 & 25 & 130 & 8 & 11 & 3.0 & 2.5 & 1.0 & 2.0 & 2.0 & 2.0 & 2.0 & 3.5 & 3.5 & 9.0000 \\ 17 & 35 & 130 & 8 & 11 & 3.5 & 2.0 & 1.0 & 2.0 & 2.5 & 2.5 & 3.0 & 3.0 & 3.0 & 9.5833 \\ 18 & 30 & 120 & 4 & 4 & 2.5 & 2.5 & 2.0 & 2.0 & 3.5 & 1.5 & 3.5 & 4.0 & 3.0 & 9.7083 \\ 19 & 35 & 120 & 12 & 11 & 3.5 & 3.0 & 1.0 & 3.0 & 2.0 & 3.0 & 1.5 & 2.5 & 3.0 & 9.9167 \\ 20 & 35 & 120 & 8 & 18 & 2.0 & 2.5 & 2.0 & 4.5 & 1.0 & 2.5 & 2.5 & 3.0 & 3.0 & 9.0417 \\ 21 & 25 & 120 & 8 & 4 & 1.0 & 3.0 & 2.0 & 3.0 & 2.0 & 1.5 & 5.0 & 4.5 & 3.0 & 9.0417 \\ 22 & 30 & 130 & 12 & 11 & 2.0 & 3.5 & 2.5 & 3.5 & 2.0 & 2.5 & 3.0 & 4.0 & 3.5 & 10.2917 \\ 23 & 25 & 120 & 12 & 11 & 1.0 & 3.0 & 2.0 & 3.5 & 1.0 & 2.0 & 2.5 & 4.5 & 4.0 & 8.4167 \\ 24 & 30 & 110 & 8 & 18 & 2.0 & 1.5 & 3.0 & 5.0 & 1.5 & 3.5 & 2.0 & 3.5 & 4.5 & 10.8033 \\ 25 & 35 & 120 & 4 & 11 & 2.0 & 2.0 & 2.5 & 3.5 & 2.0 & 2.0 & 3.5 & 4.5 & 4.5 & 9.8750\end{array}$

\section{$\underline{\text { Summary }}$}

The use of response surface designs and models enabled the food scientists to focus on selected ingredients to reduce fat content while maintaining similar sensory characteristics of the high fat content control muffin. The food scientists had problems modifying their initial 
formulation and acquired help from the statistician. The results were not ordinary because of the multivariate response. A score function was computed, a linear combination of the measured variables and the score was analyzed via a response surface model. A score of zero was desired, but the resulting response surface did not have a minimum. The better muffin formulations occurred on the boundary of the design space and a grid search was used to select candidate formulations for further evaluation.

\section{$\underline{\text { References }}$}

Chambers, E., Bowers, J.A., and Dayton, A.D. (1981). Statistical Design and Panel Training/Experience for Sensory Analysis. J. Food Sci., 46:1902.

Driskell, J.A. (1990). Nutritional Quality of Diets for the $21^{\text {st }}$ Century: Introduction. J. Food Quality. 13:1.

Falconer, D.S. (1964). Introduction to Quantitative Genetics, The Ronald Press Co., New York.

Giovanni, M. (1983). Response Surface Methodology and Product Optimization. Food Technology. November 41.

Hopper, P.E. (1990). The Role of the Food Industry in Helping Americans Improve the Nutritional Quality of their diets. J. Food Qualify, 13:59.

Joglekar, A.M., and May, A.T. (1987). Product Excellence Through Design of Experiments. Cereal Foods World. 32 (12) 857.

Mason, Robert L., Gunst, Richard F. and Hess, James L. (1989). Statistical Design and Analysis of Experiments, New York: John Wiley \& Sons, Inc.

National Center for Health Statistics. Month Vital Statistics Report, Vol. 37, No. 1, April 25, 1988.

SAS Institute Inc. (1987). SAS/STATTM Guide for Personal Computers, Version 6 Edition, Cary, NC: SAS Institute Inc.

United States Department of Agriculture and Department of Health and Human Services. Nutrition and your Health: Dietary Guidelines for Americans. $2^{\text {nd }}$ ed. Washington: USDA/DHHS, 1985.

U.S. Department of Health and Human Services. Surgeon General's Report on Nutrition and Health. Washington: Govt. Printing Office, 1988. 


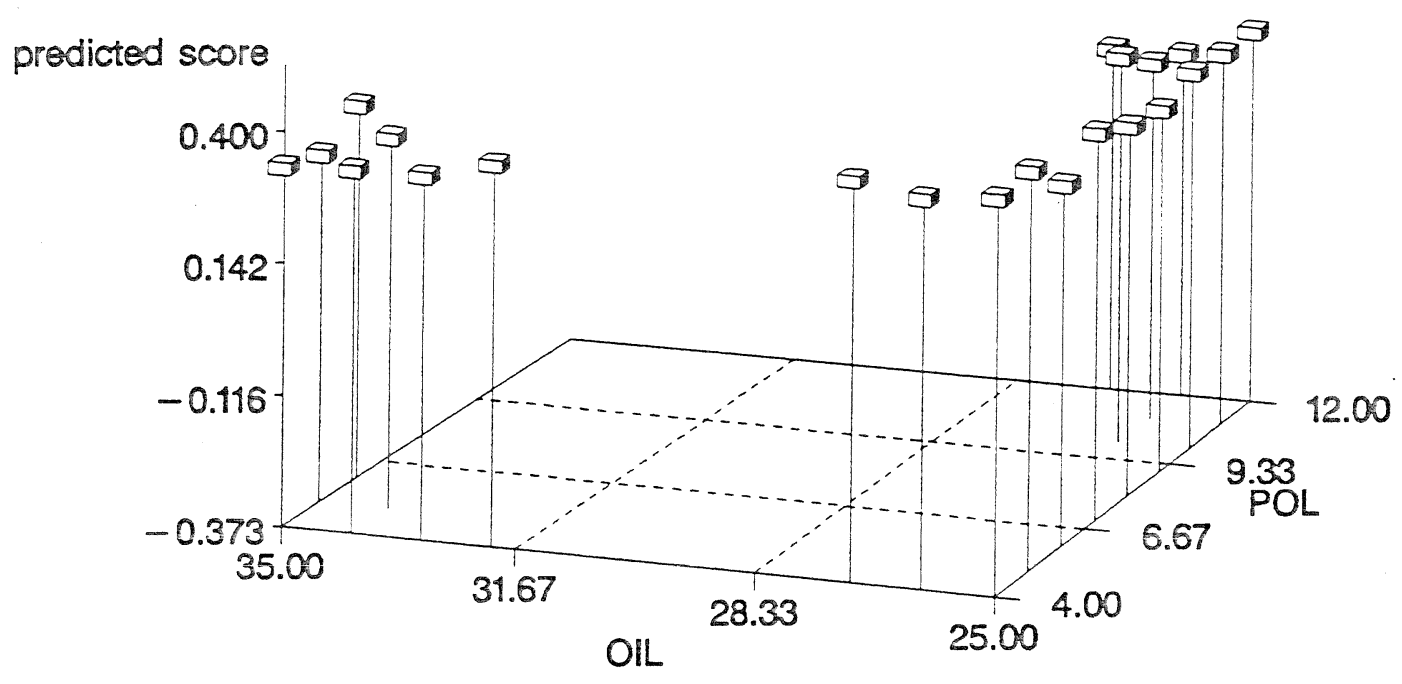

Figure 1

DEPARTMENT OF STATISTICS, KANSAS STATE UNNERSITY

$$
\begin{gathered}
-.4<\text { pscore }<+.4 \\
\text { OIL BY EWP }
\end{gathered}
$$

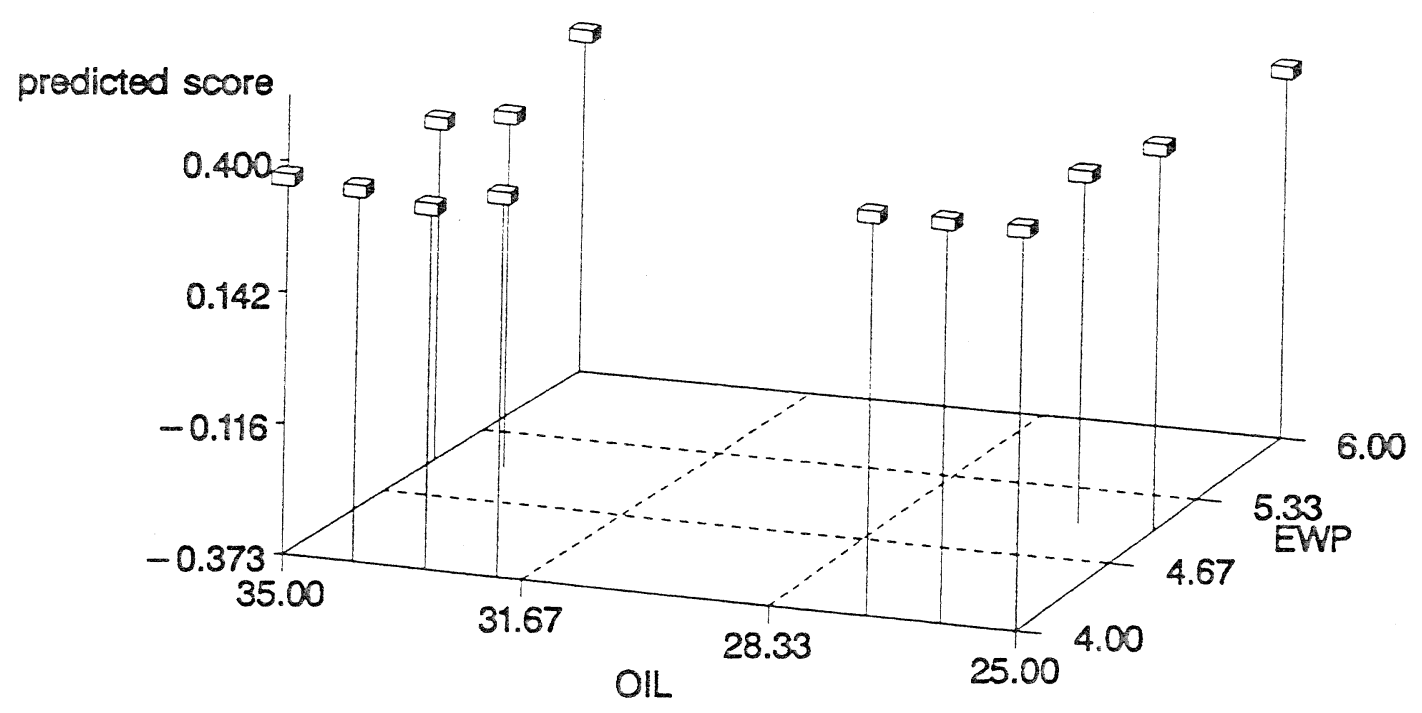

Figure 2 
$-.4<$ pscore $<+.4$

OIL BY H2O

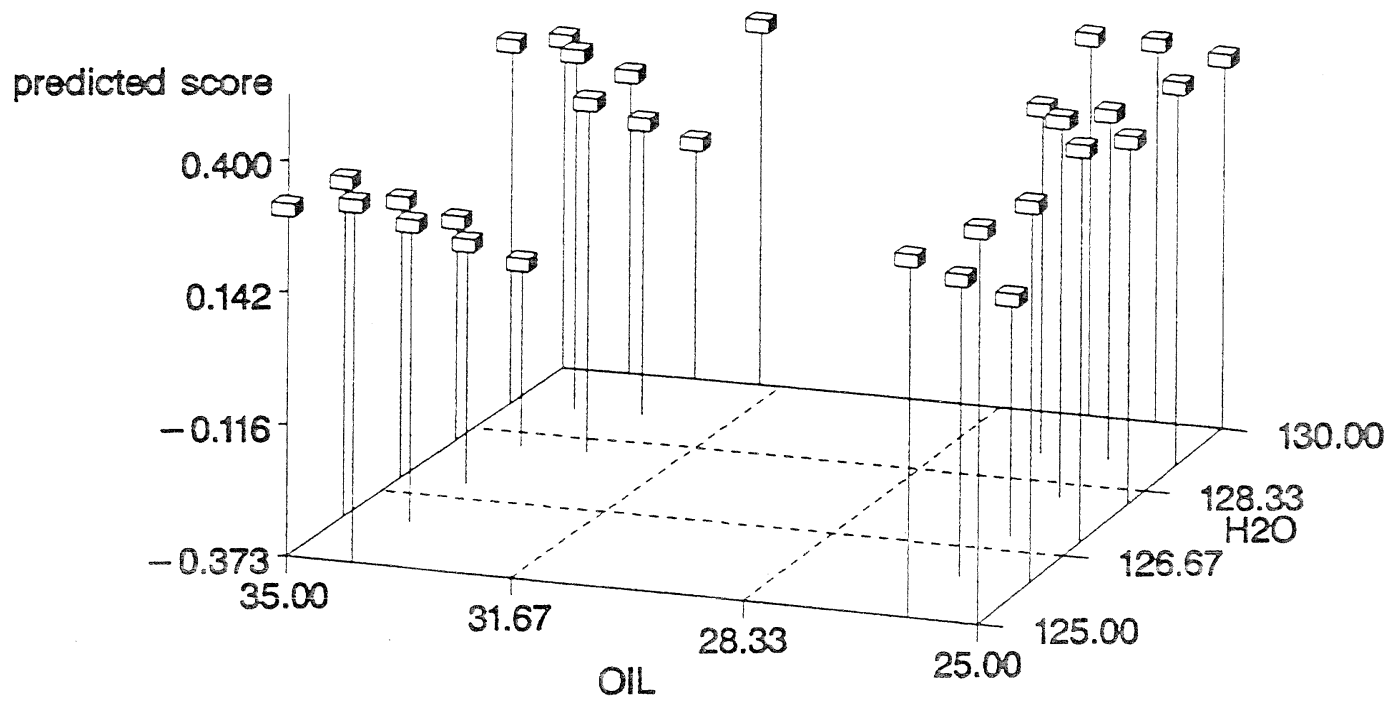

Figure 3

DEPARTMENT OF STATISTICS, KANSAS STATE UNNERSITY

$$
\begin{gathered}
-.4<\text { pscore }<+.4 \\
\text { POL"EWP }
\end{gathered}
$$

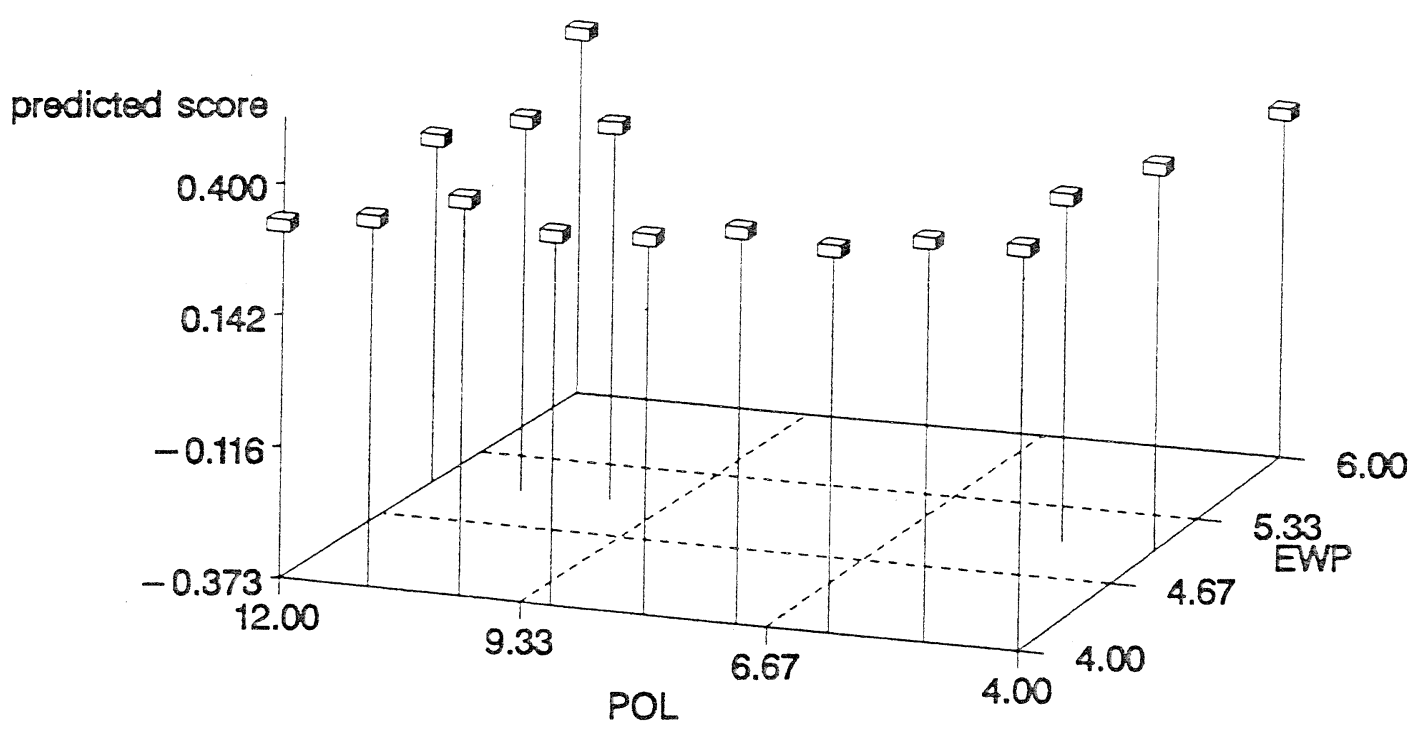

Figure 4 


$$
\begin{gathered}
-.4<\text { pscore }<+.4 \\
\text { POL*H2O }
\end{gathered}
$$

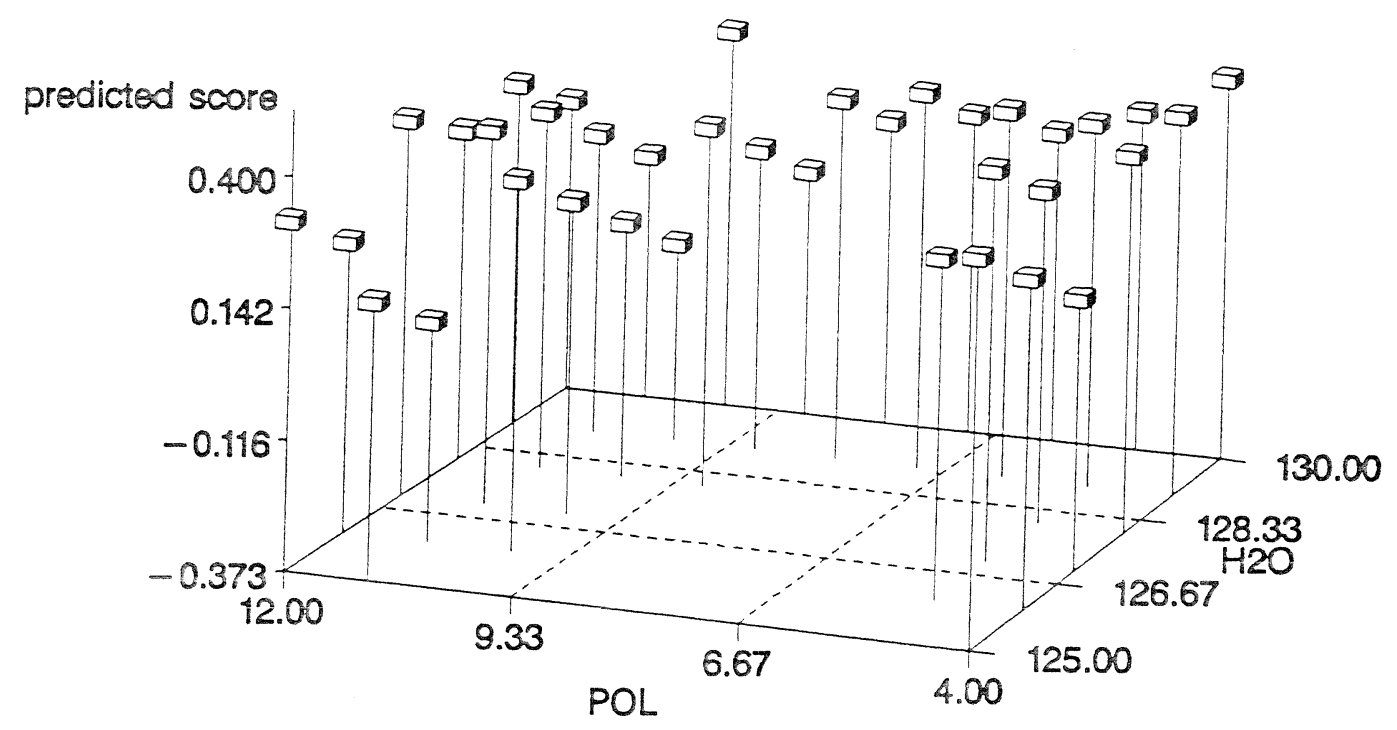

Figure 5

DEPARTMENT OF STATISTICS, KANSAS STATE UNNERSITY

$-.4<$ pscore $<+.4$

EWP $H 2 \mathrm{O}$

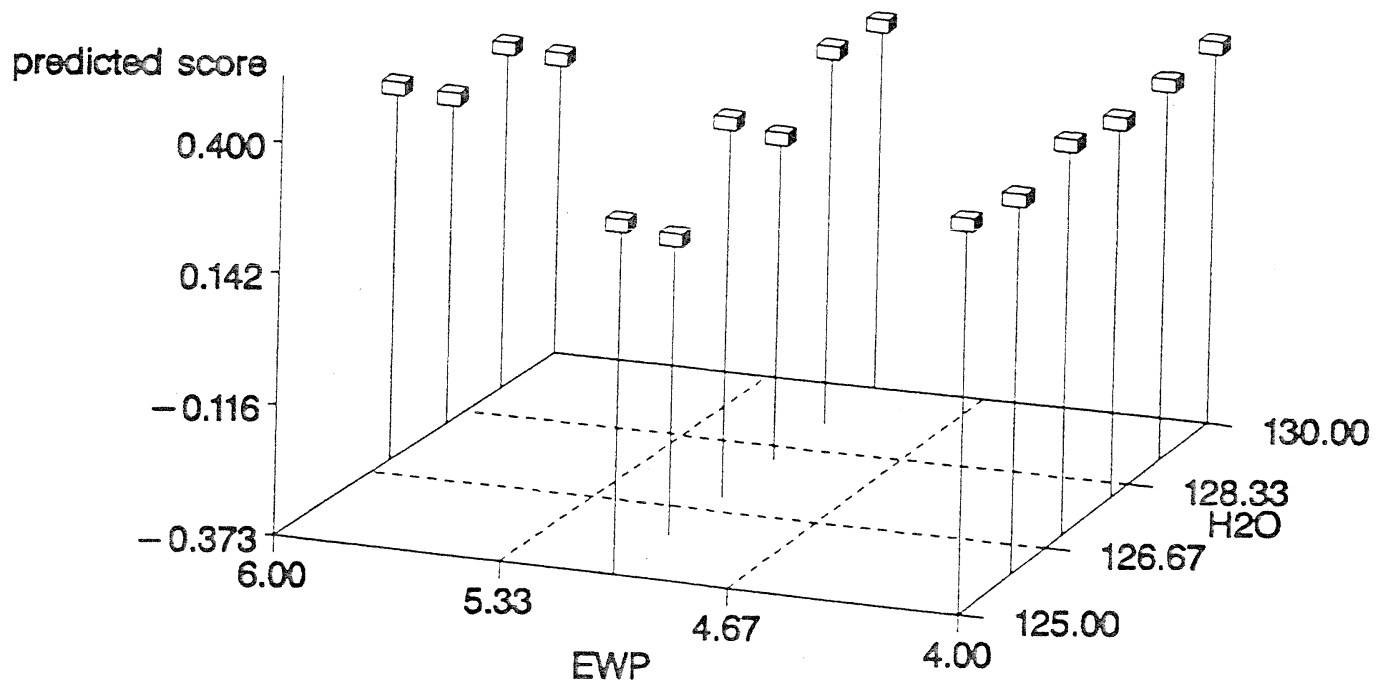

Figure 6 